\title{
Steel wire reinforced composite polyethylene pipe: the new technology for paste reticulation
}

\author{
RT Pearce Backfill Pipeline Solutions Pty Ltd, Australia \\ MB Revell Backfill Pipeline Solutions Pty Ltd, Australia
}

\begin{abstract}
Since the introduction of paste backfill into underground mining operations in the 1990s, transport of paste underground has been primarily completed using steel pipes. Steel pipes have been required due to the relatively high friction loss of the thick paste material and therefore the moderately high operating pressures realised through the piping system. Steel pipes are both heavy and rigid which results in them being labour intensive to install in the underground environment. In most other underground mine applications high density polyethylene pipe (HDPE) is used, however its use in paste backfill is limited due to the low maximum allowable operating pressures (MAOP) of HDPE. To overcome the short comings of steel and HDPE pipe for paste fill transport, a new technology known as steel wire reinforced composite polyethylene pipe (SRCP) is now becoming widely used. SRCP pipe technology provides the high pressure benefits of steel piping, along with the low weight, corrosion resistance and flexibility properties of HDPE. This paper outlines the history of $S R C P$, the products details, how SRCP is used in a modern paste fill system and a number of case studies of its use in Australian and African underground mining operations.
\end{abstract}

Keywords: paste, reticulation, SRCP

\section{$1 \quad$ Introduction}

Underground paste technology was first introduced on a major scale in the early 1990s in Canada. Paste technology differed from the hydraulic fill (sandfill) backfill technology that had existed up to that time by including a much higher portion of fine tailings material. In hydraulic fill, this fine material was removed. As a result, compared to hydraulic fill, paste was a much thicker product that tended not to settle. This major change in material characteristics impacted both the method of production of the fill and how the material was transported underground.

Due to the thick nature of the paste fill, much higher friction losses result. Therefore, if transporting the material long distances, these higher friction losses result in higher overall system operating pressures. From these initial systems right the way through to more recent paste fill installations the material is transported through steel pipes that can withstand the relatively high induced pressures. Whilst there are a wide range of pressures in operating paste fill systems, on Australian and African gravity systems based on personal experience typical maximum operating pressures range from 3,000 to $8,000 \mathrm{kPa}$.

Steel pipe is characterised by being both heavy and rigid. In complex underground environments both these characteristics result in the steel pipes being labour intensive to install and, in some cases, create a number of safety risks. In paste fill systems, high density polyethylene (HDPE) pipe has been used wherever possible. The low weight and flexibility of HDPE results in installation rates typically three to four times that of steel. Readily available HDPE pipe is, however, limited to maximum allowable operating pressures of up to $1,700 \mathrm{kPa}$ and, therefore, HDPE is only able to be used for short lengths at the ends of the system.

In 2018 a new technology known as steel wire reinforced composite polyethylene pipe (SRCP) was introduced into the backfill industry. This paper outlines what SRCP is, its background, and the benefits of using SRCP in a modern paste fill system. 


\section{What is SRCP?}

As shown in Figure 1, SRCP is constructed with an inner layer of polyethylene (PE100) covered with cross helically wound layers of steel wire and covered with a protective layer of PE100. Both sides of the layer of steel wire are coated with an adhesive to bond the polyethylene to the metal. Figure 2 shows the process of winding the steel wires around the pipe. The number and diameter of the steel wires is modified depending on the pipe pressure rating.

SRCP may be considered as a composite pipe. Due to its inner and outer layers being PE100 polyethylene, it possesses all the same corrosive and friction loss reducing properties of normal HDPE. The inner hidden layer of steel provides the strength so that the higher pressures typical of steel pipe may be achieved.

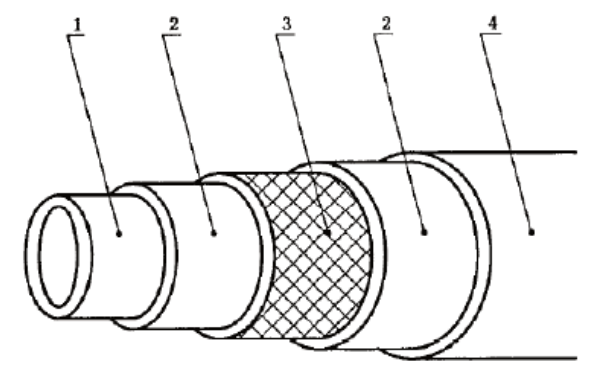

\section{Figure 1 SRCP layers of construction}

1 - Inner layer of PE100.

2 - Adhesive resin layers.

3 - Steel wire mesh skeleton.

4 - Outer layer of PE100.

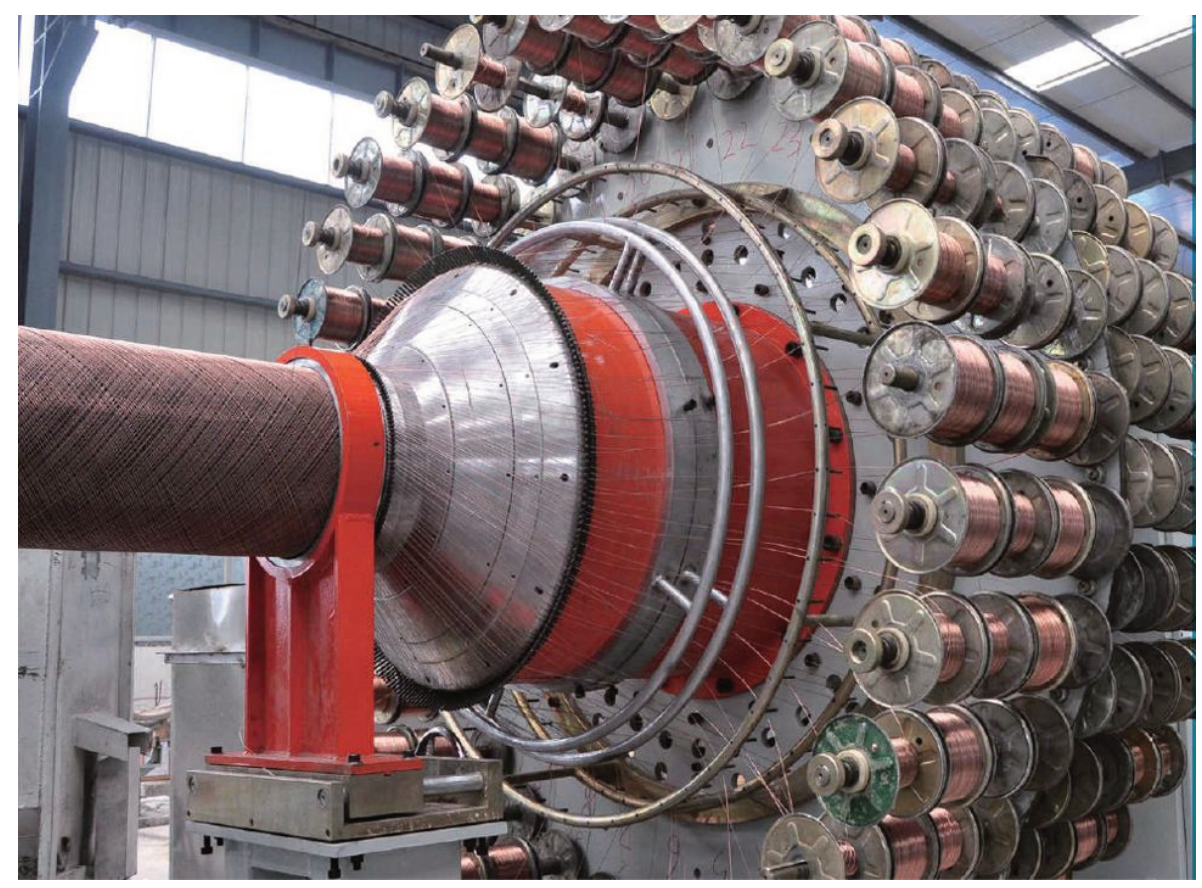

Figure 2 Manufacture of SRCP 


\section{The history of SRCP}

Reinforced plastic-based pipes (reinforced thermoplastic pipe or flexible composite pipe) have been in existence for around 30 years. These pipes were first developed for the major oil and gas companies as the demand for non-corrosive pipes expanded. The primary focus of this technology was and still is on single piece long length pipelines. These RTP or FCP pipes are relatively expensive and have continued to be focused on the oil and gas markets.

SRCP technology was born in China in the early 2000s and up until 2018 penetration of the technology outside of China was almost non-existent. The SRCP pipe was developed for similar reasons to RTP, whereby non-corrosive conduits were required that could also handle much higher pressures than unreinforced HDPE. The major difference is that the SRCP technology was developed by companies that typically had their history in HDPE pipe manufacture and who supplied pipe as lengths into the mining and infrastructure industries. As Chinese infrastructure boomed, SRCP technology advanced, and both government and universities worked with industry to develop the standards (GB/T32439-2015) by which SRCP is manufactured and tested. These standards are effectively an extension of HDPE standards.

SRCP is produced in pressures up to $7 \mathrm{MPa}$ for diameters up to $200 \mathrm{~mm}$ outer diameter (OD). Above 200 OD, the maximum pressure rating of the SRCP decreases steadily to $1.25 \mathrm{MPa}$ for the maximum SRCP size available of $1,000 \mathrm{~mm}$ OD.

In China, the SRCP industry is estimated to be USD 500 million annually. SRCP is used throughout all areas of the mining industry and infrastructure (i.e. water distribution).

In 2016, Jamie Chaffey of Stripes Engineering discovered SRCP and so started the journey of developing SRCP for the Australian and global paste fill industry.

\section{$4 \quad$ Making SRCP suit the needs of paste}

When the authors were presented with SRCP in early 2017, it appeared to be the holy grail for underground piping providing a light weight pipe solution, that had working pressures approaching steel and costs that were competitive with steel piping.

Within China, SRCP is made in variable lengths and is almost exclusively joined using stub ends and backing flanges as shown in Figure 3. Within the paste fill industry, flanges are very rarely used and instead mechanical couplings (e.g. Victaulic grooved couplings) are used. This is because the flanges are expensive, slow to install, and add huge amounts of weight to already heavy steel pipe. Therefore, the major change required was to develop a system to join the SRCP using a grooved coupling system as flanges would have negated the weight benefit of the SRCP. Over a period of 12 months the new end connections were developed and tested both internally and externally by Victaulic to ensure the SRCP Factor of Safety of three was upheld for the new end connection (Figure 4). 


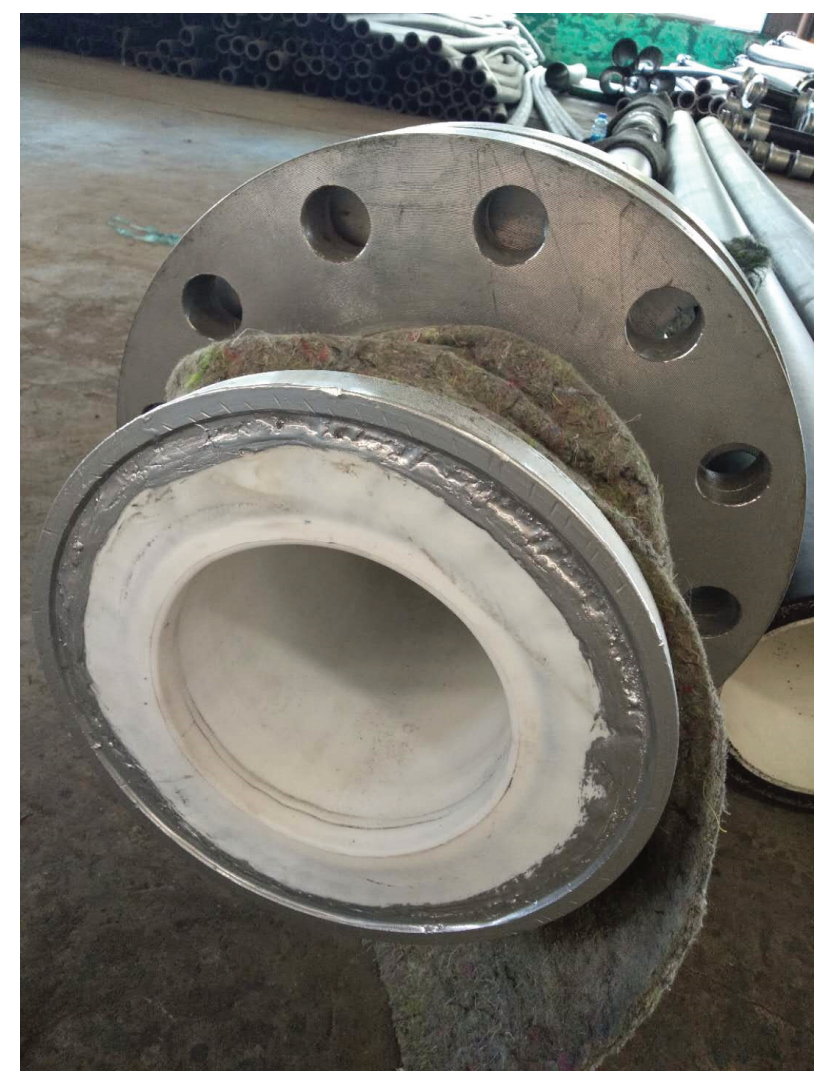

Figure 3 SRCP with backing flange connection method

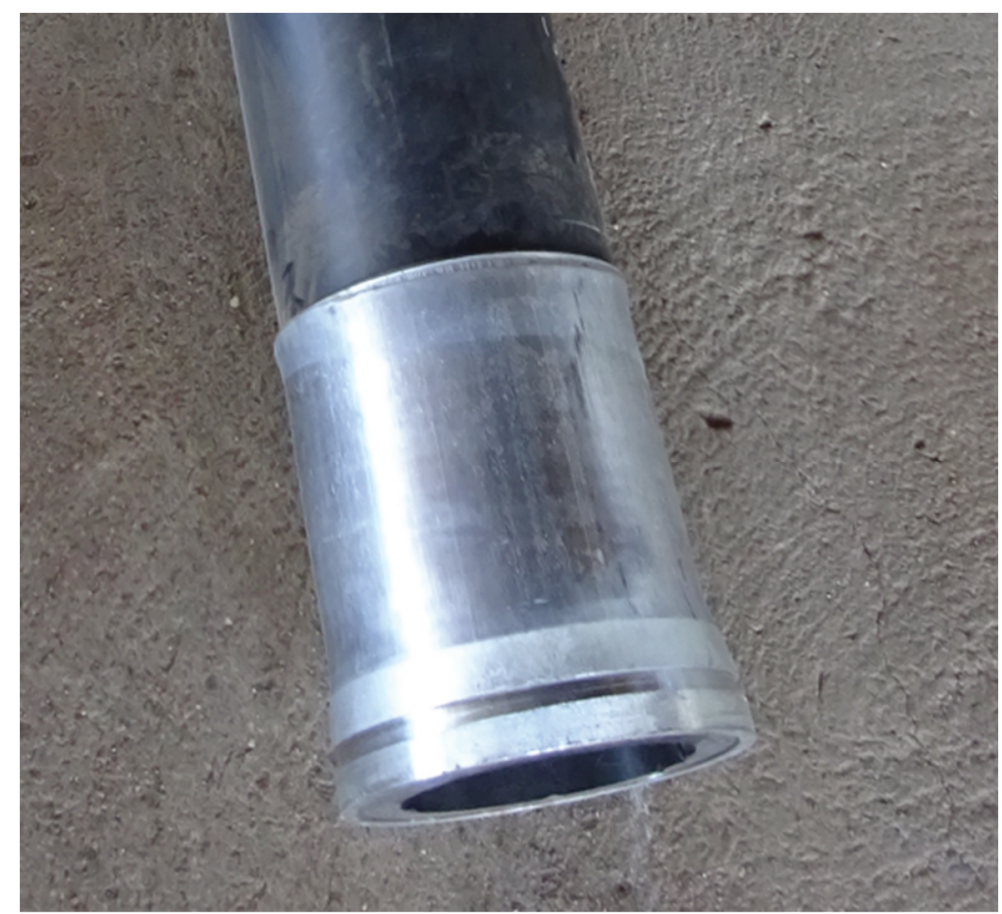

Figure 4 SRCP with grooved end connection to suit Victaulic coupling

Figure 5 shows an example of a typical burst test, highlighting the failure mode of the SRCP and failure pressure of $22,400 \mathrm{kPa}$ which is greater than three times the $7,000 \mathrm{kPa}$ rating of the sample tested.

In conjunction with the mechanical coupling end development, the SRCP standards were prepared for the different global markets. This step was relatively straightforward since Chinese HDPE and thus SRCP was 
developed around global ISO standards. As such, the raw HDPE and steel wire materials, manufacturing tolerances, and testing regime align with globally accepted and proven methods.

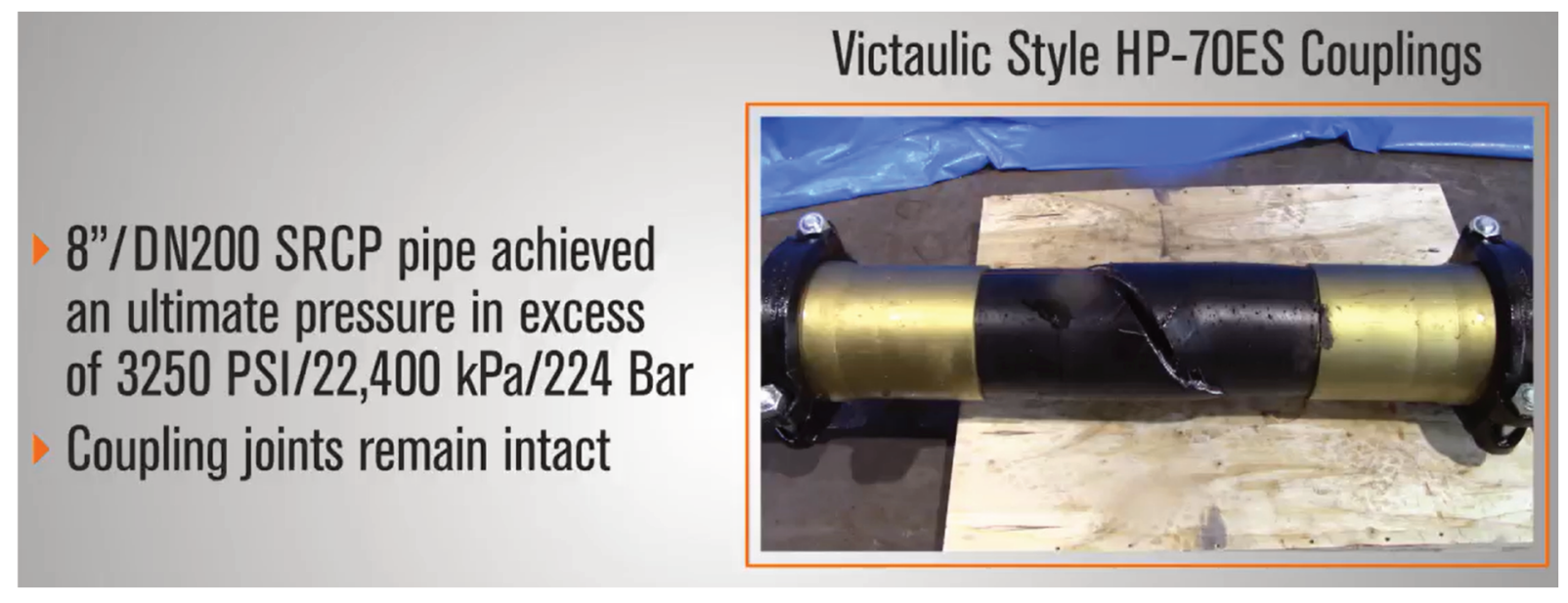

\section{Figure 5 External Victaulic testing of SRCP}

The final step of the development process was site testing. This was certainly the longest and toughest step of the entire process. Whilst mining companies are adopting new technology at rates never seen before, the fact remains that change is still a challenge especially when paste distribution has only ever used steel pipe. The other major challenge, that continues to this day, is that SRCP does not look much different to HDPE. Many people cannot believe that the pipe will be able to handle pressures any higher than unreinforced HDPE. Several mines subsequently conducted their own onsite pressure tests and many had the expectation that it would fail around the 5,000-6,000 kPa level just like HDPE. It took tests such as these, and then subsequent $20,000-50,000 \mathrm{~m}^{3}$ paste production trials before the industry started to become more comfortable with the product.

It must be highlighted that the use of SRCP in Western applications is still very much in its infancy, and many more individual site trials will continue before it becomes even more widely used.

\section{How is SRCP designed into a paste system?}

The quick answer to this question is that the use of SRCP, and the design methods, are no different to the current and historical methods of designing paste reticulation systems with steel.

As previously described, the historic need for steel pipes in paste systems is due to the moderately high operating pressures. The high operating pressures are a function of the thick consistency of paste fill and, therefore, the relatively high friction loss $(4-10 \mathrm{kPa} / \mathrm{m})$. As a result, a typical paste system will have operating pressures of 3,000 to $8,000 \mathrm{kPa}$ through large portions of the system. For example, if there is a horizontal run of $750 \mathrm{~m}$ and a friction loss of $6 \mathrm{kPa} / \mathrm{m}$ then a maximum operating pressure of 4,500 kPa results on that level.

It is important to recognise that the relatively high operating pressures are not a function of how deep the mine is. The depth of the mine only impacts the maximum pressure that a paste system may be exposed to in the event of a blockage.

For most modern mines that are well below $500 \mathrm{~m}$, even steel pipe systems are not designed to handle the full static pressure in the event of a blockage. Whilst it is possible to make a steel pipe system handle extremely high pressures, the cost and weight of the piping system becomes unviable. Therefore, most paste systems have over-pressure protection devices (e.g. burst pipes) to protect the piping system. If a blockage does occur, the pipe system will fail in a controlled location to eliminate the hazard to underground personnel. 
Most gravity paste systems in Australia are designed for a maximum pressure of $10,000 \mathrm{kPa}$. This is dictated primarily by the single-groove mechanical couplings that are used, and this pressure is generally well above the maximum operating pressures.

The design of a paste system that uses SRCP is similar to steel. The only difference is that the maximum operating pressure of SRCP at 30 degrees Celsius is $6,100 \mathrm{kPa}$ (SRCP is derated with temperature in the same way as unreinforced HDPE).

As a result, burst pipes are still required to be used in the system in the same way as steel; the burst pressures are simply lower.

SRCP may be used in some new systems as a complete replacement for steel where the maximum system operating pressures are below the maximum allowable operating (MAOP) for SRCP. Alternatively, depending on the design of the backfill system, operating pressures in some parts of the system may approach or exceed the $6,100 \mathrm{kPa}$ limit of SRCP. In such systems, steel is used in the higher-pressure parts of the system or often what is referred to as the 'body of the Octopus'. For the 'arms of the Octopus', instead of steel, SRCP is used. As an example, for a system with a friction loss of $6 \mathrm{kPa} / \mathrm{m}$ then SRCP may be used for 'arm lengths' up to $1,000 \mathrm{~m}$.

In brownfields paste systems that were commissioned prior to the existence of SRCP pipe, SRCP is typically being used in one of two ways. The first way is in large open stoping environments as the 'arms to the Octopus' as described above. The second way is in longitudinal retreat operations with long ore drives. The SRCP is used in these long ore drives instead of installing steel.

\section{Why use SRCP?}

SRCP has several key advantages compared to steel in mine paste fill applications:

- SRCP weighs a quarter of the weight of schedule 80 steel pipe. Handling of SRCP pipe is thus much easier than steel, providing a much safer working environment specifically around strains to the body, and hand injuries.

- The internal surface of SRCP pipe is HDPE which is a lower friction material than steel and thus aids in the flowability of the backfill piping system.

- The outer surface of SRCP pipe is also HDPE (except for the steel end connections). Thus, the majority of the pipe surfaces are non-corrosive and no additional surface protection is required if a corrosive environment exists.

- HDPE exhibits favourable wear properties over carbon steel and thus SRCP provides a lower wear system and less pipe maintenance costs.

- SRCP is a semi-flexible material. It can be bent to nominally 200 times its nominal diameter during installation which greatly increases the efficiency of installation. Fewer elbow fittings are required and a faster rate of installation is achieved compared to steel. SRCP install rates are similar to traditional HDPE, so around three to four times as fast as steel.

Table 1 provides a comparison of the costs for a 200 NB schedule 80 steel pipe system assuming $4 \mathrm{~m}$ pipe lengths versus a 200 OD SRCP system using $5.8 \mathrm{~m}$ pipe lengths. Both systems use Victaulic HP-70ES 200 NB couplings.

The costs are based on the SRCP install rate being 3.6 times the steel install rate as determined through various site studies currently using SRCP.

It is highlighted that if the required pressure rating of the SRCP system is only 5,500 kPa, then Victaulic style 177 QuickVic couplings may be used. These are a lighter weight, lower cost coupling that are designed to be installed faster than Victaulic style HP70 couplings. This further reduces the total installed cost for the SRCP system to approximately AUD 300/m. 
Table 1 Cost of piping system based on a $100 \mathrm{~m}$ pipe run

\begin{tabular}{lll}
\hline Heading & Steel 200 NB schedule 80 system & 200 OD SRCP system \\
\hline $\begin{array}{l}\text { Pipe costs } \\
\begin{array}{l}\text { Coupling and hanger material costs } \\
\text { (hangers, bolts, couplings, elbows, etc.) }\end{array}\end{array}$ & AUD 163/m & AUD 190/m \\
$\begin{array}{ll}\text { Installation cost } & \text { AUD 250/m }\end{array}$ & AUD 74/m \\
Total cost & AUD 532/m & AUD 70/m \\
\hline
\end{tabular}

\section{$7 \quad$ Case studies}

This section presents four case studies. The first is of an African mine which is the first new paste fill system that has had SRCP included into the design from the outset. The remaining case studies illustrate how SRCP is being introduced into brownfields paste systems.

\subsection{Anglogold Ashanti Obuasi mine, Africa}

In 2020/21, the Obuasi paste fill system was constructed in Ghana, which is due to begin paste placement in late 2021. The entire system is being installed as a modern automated paste fill system with delivery of paste to over 1,000 vertical metres underground.

The use of SRCP into the design of new paste fill systems commenced in 2019, and Obuasi represents the first project where SRCP has been fully integrated into the system design and subsequently installed.

The system consists of a long $600+\mathrm{m}$ surface borehole, followed by a $400 \mathrm{~m}$ horizontal run on the first level, and a $200 \mathrm{~m}$ internal borehole followed by another $400 \mathrm{~m}$ horizontal run. A short internal borehole then delivers paste to the first filling horizon where fill is transported a further horizontal distance of up to $600 \mathrm{~m}$. Filling horizons occur every $20 \mathrm{~m}$ and typically fill is distributed up to $600 \mathrm{~m}$ in an east and west direction. This layout is shown in Figure 6.

During the design stages, the client's preference was to build the entire system from SRCP only. However, the decision was made to install the top two levels as steel, to provide a system that could handle very high pressures that may result from system blockages and/or human errors. On these top two levels, SRCP burst pipes as shown in Figure 7 are installed in 'no entry' areas to ensure the system fails in a controlled location in the event of an over-pressure event.

From the first filling horizon down, all piping is 200 OD $7 \mathrm{MPa}$ SRCP. The major reason for SRCP selection at this mine was the reduced cost, and more critically, the significant time savings of installing SRCP. In developing any new mine, there is a massive number of tasks required, and often limited resources. The experienced paste supervisor who is operating this project had not used SRCP before. Installation of the capital SRCP extent occurred so much quicker than installing steel pipe which subsequently has freed up weeks of availability for the crew to complete other critical tasks. Whilst the light weight was seen as a major advantage, the major factor identified by the paste supervisor that sped up the works significantly was the small amount of flexibility in SRCP. This significantly reduces the number of shallow angle elbows required, and provides much greater degree of flexibility in installing the pipe compared to steel. 


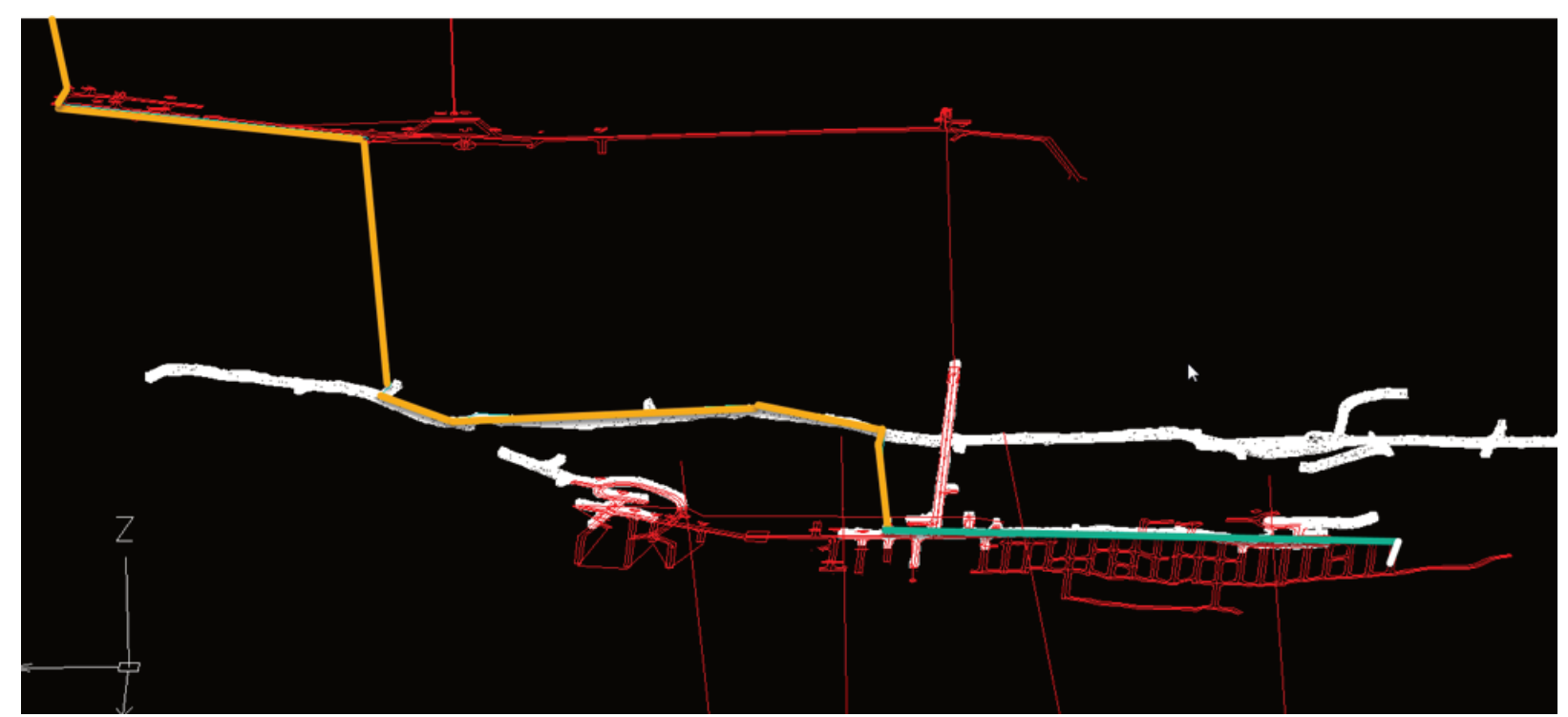

Figure 6 Mine 1 layout (yellow represents steel and green SRCP)

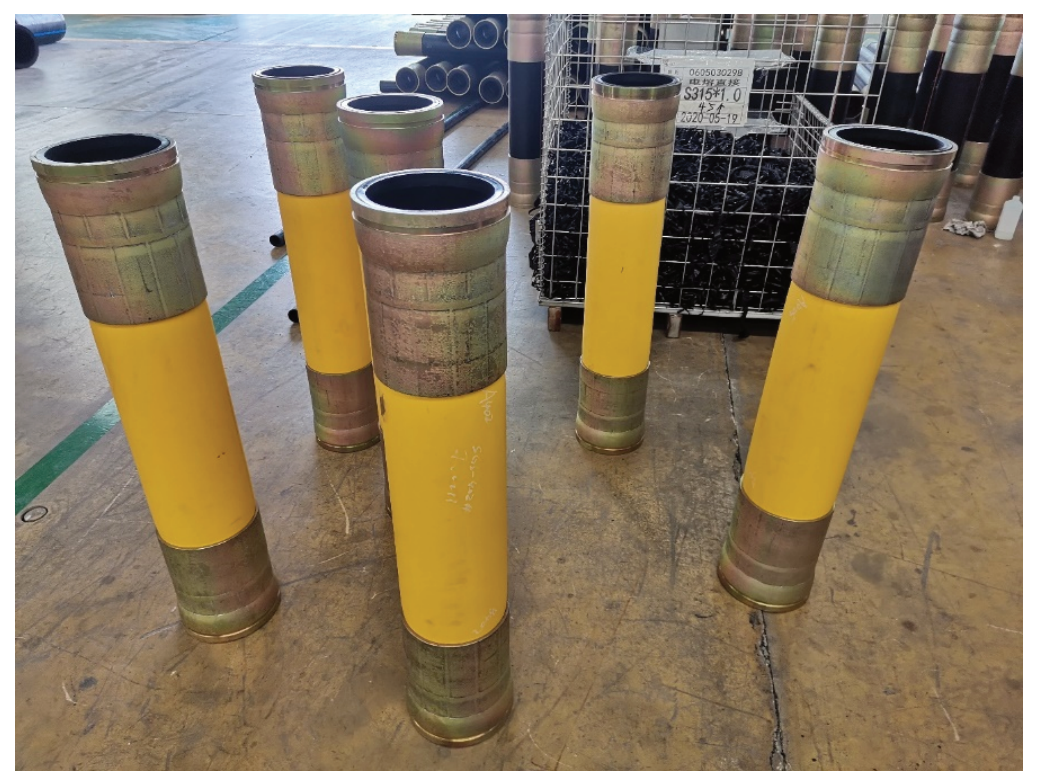

\section{Figure 7 SRCP burst pipes}

\subsection{Mine 2 - Australia}

Mine 2 is one of Australia's first paste fill operations. Having been an early paste system, over the years this site has experienced significant change, and furthermore, the system has expanded massively.

On the underground transport of paste, prior to the introduction of SRCP, the majority of pipe used onsite was schedule 80 steel pipe with double-groove Victaulic 808 couplings. The double-groove couplings were not used for the pressure rating, but rather were a legacy design to manage the dynamic movement of the system operating in batch production. System changes since this time have removed the major dynamic loading and thus Victaulic 808 couplings are no longer necessary.

As part of a modernisation to this system, 200 OD 3.5 MPa SRCP was introduced in mid-2019 joined by single-groove HP70ES couplings. After going through an exhaustive 12-month trial process, SRCP is now used for almost all extensions to the underground system (i.e. arms of the Octopus). 
At this site, the installation crew connect four lengths of SRCP together on the ground prior to using the integrated tool carrier mobile machine to assist in lifting it to the backs for securing with chain. The crews install pins and saddles $1.5 \mathrm{~m}$ either side of each coupling.

This site installs SRCP in the same manner as they would typically install HDPE, and as shown in Figure 8 they take advantage of its flex to get around corners. To date, this site has averaged install rates of SRCP greater than five times that of steel, and they along with Mine 1 are the largest global users of SRCP.

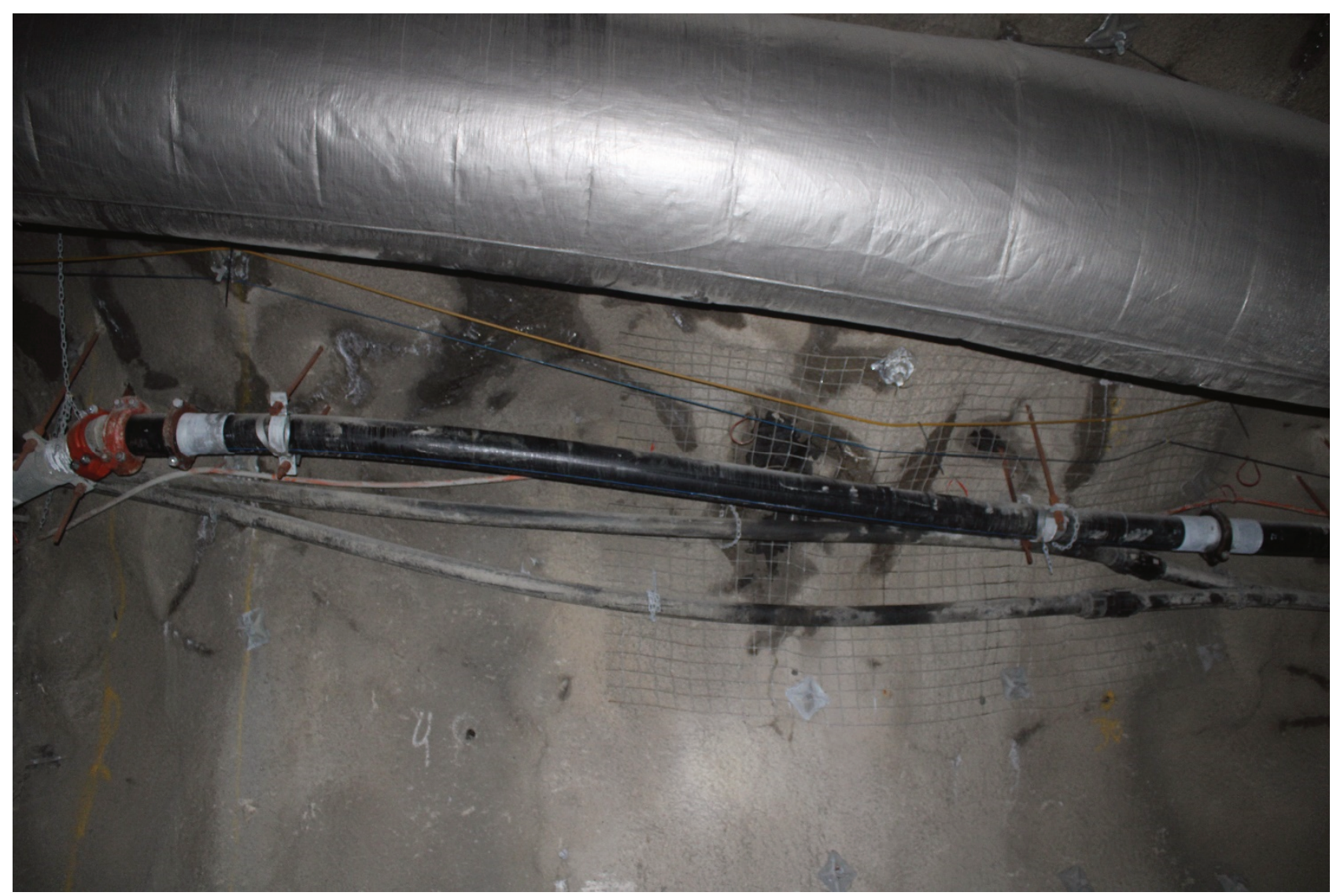

\section{Figure 8 SRCP installed at Mine 2}

This site also installed an overland paste pumping system in 2020, and throughout this system SRCP burst pipes are used as over-pressure protection in the event of a blockage.

\subsection{Western Areas Spotted Quoll and Flying Fox - Australia}

Spotted Quoll and Flying Fox were the first global paste sites to adopt SRCP, and they use both 200 OD and 160 OD 7 MPa SRCP in the two mines. Both mines employ a longitudinal retreat mining method with relatively long ore drives.

When SRCP was first presented to the authors in 2017, its use instead of steel in long ore drives was seen as the major market for the technology. Almost all sites employing paste in longitudinal retreat mining have fill horizons every 15-25 m, and if the ore drives are not too long, HDPE pipe is used solely in the ore drives. Many sites, however, have ore drive lengths that mean HDPE does not have an adequate pressure rating.

The major advantages this site has found using SRCP are safety and the small level of flex inherent in SRCP. The ore drives at this mine are relatively low in height and access for machinery is difficult. As a result, hanging of steel pipe in these restricted areas is extremely difficult and hazardous. SRCP has removed this issue being one quarter the weight of steel and again the same method as hanging HDPE pipe may be used. 


\subsection{Gold Fields Western Australian mines - Australia}

In late 2019, Gold Fields were looking at ways to improve the safety of their paste fill operations. One specific area was the installation of the steel borehole toe and collar pipes. Steel borehole toe and collar pipes are installed regularly throughout all paste fill operations into the top and bottom of unlined internal boreholes. Due to their weight and the awkward geometry of the installation process, it is a relatively high-risk activity. Gold Fields personnel were looking to develop a complicated and expensive handling device to install the toe/collar pipes. SRCP was being considered for use at the time, and the paste supervisor identified the option of using SRCP as the toe/collar instead of steel. Subsequently, Gold Fields have started to employ SRCP toe/collar pipes where one end of the pipe is grooved, and the other is plain ended as seen in Figure 9. These toe/collar pipes are matched with no weld pipe supports (Australian design number 202111080), as shown in Figure 10, resulting in a safe and easy to install solution. Gold Fields St Ives have also commenced using SRCP within their ore drives.

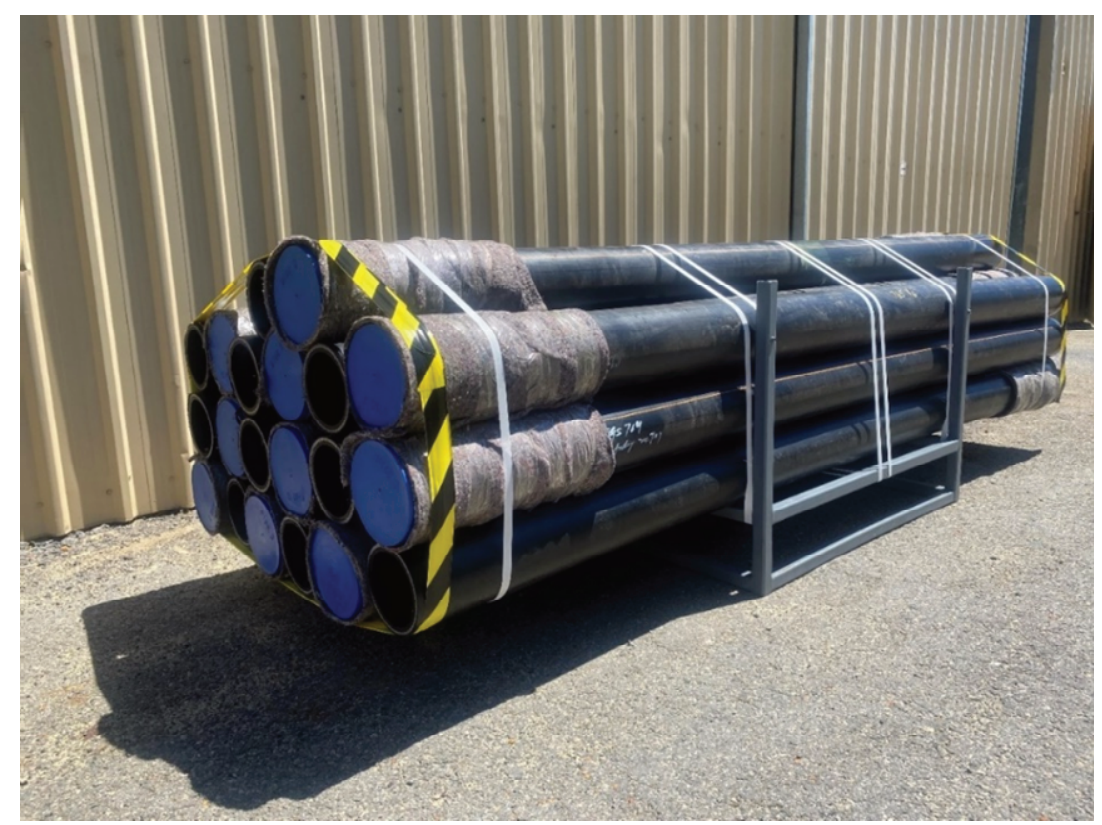

\section{Figure 9 SRCP toe/collar pipes}

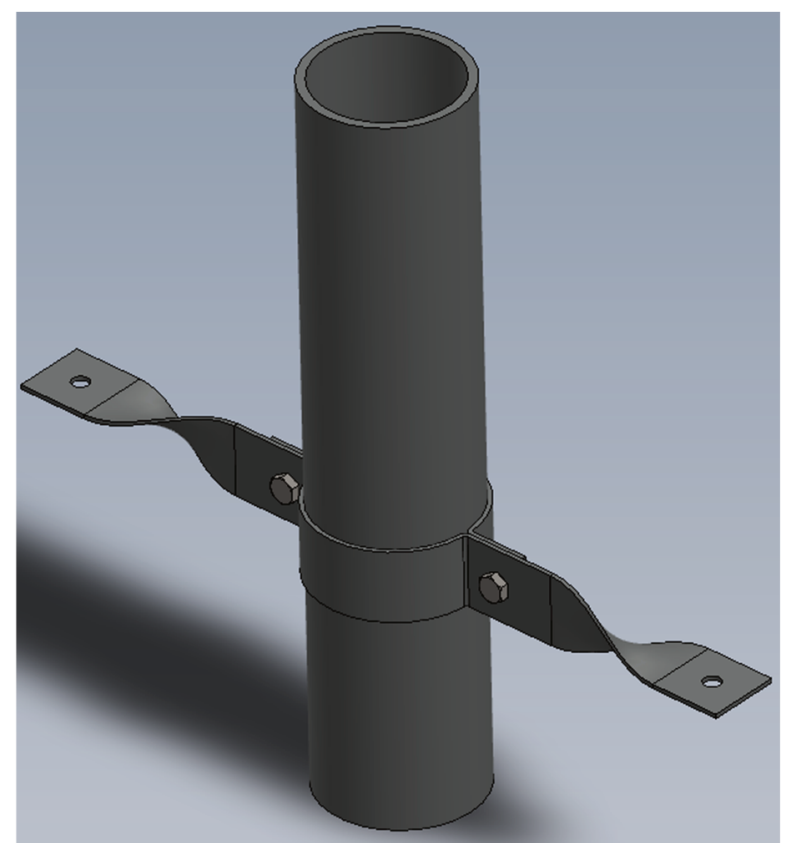

Figure 10 No weld toe/collar pipe support (Australian design number 202111080) 
This concept has now been developed further with the first threaded end SRCP currently in manufacture for a mine in Africa that will use SRCP to fully line $35 \mathrm{~m}$ internal boreholes instead of steel. Again, the main driver is safety in handling pipes in difficult conditions.

\section{Conclusion}

For many years, paste operations have been looking for a faster and safer way to install pipe for paste transportation. Previously, the only option was to maximise the use of HDPE pipe. The introduction of SRCP into the global market, connected by a grooved coupling system, now provides the seamless next-generation solution. The overarching design principles of the paste system remain the same as a steel system, and SRCP may be used as an entire replacement of steel or used strategically in combination with steel to provide the optimum system configuration.

\section{Acknowledgement}

The authors acknowledge the companies referred to in this paper along with their operating personnel for helping to support and develop new paste technology. 
